\title{
FATIGUE DAMAGE IDENTIFICATION IN THREADED CONNECTION OF TUBULAR STRUCTURES THROUGH IN-SITU MODAL TESTS
}

\author{
T.T. Bui ${ }^{1}$, G. De Roeck ${ }^{1}$, J. Van Wittenberghe ${ }^{2}$, P. De Baets ${ }^{2}$ and W. De Waele ${ }^{2}$ \\ ${ }^{1}$ K.U. Leuven, Department of Civil Engineering, Belgium. \\ ${ }^{2}$ Ghent University, Laboratory Soete, Belgium.
}

\begin{abstract}
The use of threaded connection is a valuable alternative to conventional welding in tubular constructions, e.g. pipelines, drill pipes and deep water risers. Those applications are normally exposed to environmental hazards - wave induced vibrations, temperature changes, etc. - as well as subjected to severe service conditions. A classical way to determine fatigue strength in many engineering situations is to calibrate material models by means of ad hoc designed experiments. Unfortunately, it is very difficult in this case even under laboratory conditions due to complicated stress and strain states in the contacting tapered helical thread surfaces of the connection. Therefore, a classical four-point bending fatigue test setup has been built with a real pipe specimen of 3.75 meter long, consisting of two standard API pipes connected by a threaded coupling, under unsymmetric (non-zero average) load control cycles. A complete vibration study has been carried out based on input-output modal tests for the entire period of the fatigue experiment. Input excitation is due to hammer impact and responses are recorded by accelerometers and by reusable dynamic strain gauges. The measured modal strains from the dynamic strain gauges allow for direct calculation of the modal curvatures, rather than deriving approximately from acceleration information. By comparing the measured modal parameters with those of a numerical model of the same structure in undamaged condition, damage detection, localization in the coupling and quantification are possible. This study leads to the following conclusion of practical use: the recent advancement in modal analysis, i.e. the reference based input-output combined deterministic-stochastic subspace identification, makes it possible to identify the structural modal properties from in-situ modal tests, which are performed while the fatigue test is ongoing. In this way the fatigue test is uninterrupted to avoid the problem of stress and strain disturbances happened in un-reversing load cycles test.
\end{abstract}

Keywords fatigue, four-point bending test, in-situ modal test, modal analysis, threaded connection.

\section{INTRODUCTION}

In tubular constructions, pieces of linepipes may be of either welded or threaded connection. Threaded construction can offer a range of benefits over welding. The main advantage is in time required to make-up a connection. Welded joint make-up is a slow process, requiring complex procedures to ensure that the weld quality is maintained. This complexity is further increased in situation, such as, a pipe-in-pipe design. Whereas, a threaded connection can be reliably made up in less than five minutes with homogeneous quality, and also has the advantage of allowing the use of high strength steels and composite materials (nonweldable) enabling the overall structure weight to be reduced.

It is believed that the threaded connection provides better fatigue resistance than welding technique, which is evitable to voids and defects. However its performance is still poorly understood. The reason is its complicated geometrical properties and its contact conditions. Therefore it is difficult to detect fatigue damage even in laboratory conditions. And also it might be problematic to develop an ad hoc experimental scheme to calibrate material model due to complicated stress states and strain developments.

Recent development in modal testing with sub-space identification algorithms [1-3] allows for a combination of deterministic and stochastic identification approaches and also both measure artificial and unmeasured ambient excitation sources are utilized. The ambient input in operational condition is considered as a useful source of excitation rather than unwanted noise. These make it possible to carry out modal analysis in a more flexible setting, suitable for large scale civil engineering applications.

Finite element updating, a special treatment of the inverse problem in which the numerical finite element model is continuously updated until differences to the extracted experimental results reach a certain threshold. Then one or several tuned parameters are identified. Although the problem is simple to state mathematically, the solution is dependent on the completeness and the quality of the extracted measured data. Careful treatment is needed in order to overcome the ill-posedness of the formulation and the illcondition of the problem. Interested readers can be referred to the authoritative book in this area by Friswell 
and Mottershead [4] and various particular applications, for examples, Teughels et al. [5] with the introduction of damage function and Reynders et al. [6] with improved experimental data treatment.

The structure of the paper is presented as follows. First, an experimental scheme is described. Then the modal analysis is performed to get meaningful data. Next, a finite element updating with two processes is presented with the final objective of getting the degrading stiffness in the connection region of the structure.

\section{THE EXPERIMENTAL PROGRAM}

\subsection{OMAX testing}

In classical Experimental Modal Analysis (EMA), the structure of interest is excited by one or several measured dynamic forces, the response of the structure to these forces is recorded, and the modal parameters in the frequency range of interest are extracted from the analysed data [7,8]. During the test, the structure is essentially isolated from its operating environment and tested in laboratory condition. Due to isolation, the excitation and the boundary conditions may therefore differ significantly from those of structure's real-life operation. Furthermore, EMA methods are in general less suitable for large scale structures, since it is very difficult, if not impossible, to create laboratory condition for testing. As an alternative, output-only or Operational Modal Analysis (OMA) techniques have therefore been developed [3]. They extract the modal parameters from the dynamic response to ambient forces and in operational condition. Consequently, they deliver a linear (modal) model of the structure around the real working point of operation. The unmeasured, ambient forces are usually modelled as stochastic quantities with unknown parameters but with known behaviour, i.e. as white noise time series with zero mean and unknown covariance. However, the existing OMA techniques suffer from several important shortcomings. The first one is that output-only measurements do not allow to determine a complete modal model, since the mode shapes can not be scaled in an absolute sense, e.g., to unit modal mass. Secondly, the ambient excitation is sometimes confined to a narrow frequency band, and as a result only a limited number of modes can be extracted with high quality from the ambient vibration data.

For these reasons, there has been an increasing interest during the last few years towards combined experimental-operational modal testing techniques, also called hybrid vibration testing or Operational Modal Analysis with eXogenous inputs (OMAX) $[9,10]$. In this technique, artificial forces are used in operational conditions. The main difference between OMAX and the traditional EMA approach is that the operational forces are included in the identified system model: they are not considered as an unwanted noise source, but as useful excitation. As a consequence, the amplitude of the artificial forces can be equal to, or even lower than, the amplitude of the unmeasured, operational forces. This is of crucial importance for the modal testing of large scale structures, since it allows to use excitation devices, e.g. actuators, impact hammers, shakers, etc., which are small and practical when compared to the ones that are needed for EMA testing.

\subsection{Experimental fatigue}

The task of monitoring the condition of structures working under variable and repeated loading conditions is important, unfortunately, challenging and often tedious when plastic deformations must be taken into account. In threaded connection of tubular constructions in large scale civil engineering application, the stress development is difficult to track due to the complicated tapered helical geometry of the connecting threads that involve frictional contact establishment. Previous studies [11,12] show that the Huber-von Mises equivalent stress in the last engaged thread zone even reaches yield in the assembling process (connection make-up). Moreover, the stress and strain states are rarely symmetric, i.e. reversing, and the structure is often exposed to varyingly repeated loading.

Therefore, it is of paramount importance to distinguish between the two modes of structures collapse under such cyclic loading, i.e. incremental collapse and alternating plasticity. Theoretically, the critical situation will be the one which has the lower plastic limit. In large scale civil engineering practice, alternating (symmetrical) plasticity - in which plastic deformation changes its sign in every cycle leading to a tendency of cancelling each other and the total deformation remains small and the structure only fails in a fatigue phenomenon after a sufficient number of cycles - is rarely the case due to complex combined loading.

At present, the kinds of cyclic tests most frequently adopted are uniaxial tests with fully reversed (i.e. alternating, symmetric) imposed displacements, which usually satisfy the requirement of simple execution. However the stress and strain states generated are nothing close to the real-life application as mentioned earlier.

Cyclic tension-torsion tests under force control are alternatively performed on thin-walled, tubular specimens [13-15], in order to produce in the specimen more sophisticated biaxial stress states which are uniform like in uniaxial tensile tests. This kind of test exhibits a complicated procedure nevertheless it is still not able to replicate the real working condition of the threaded connection. 


\subsection{Test descriptions}

With due consideration to the above mentioned difficulties, a simple full scale four-point bending test setup has been proposed to represent the fatigue test. The test setup has to ensure that the stress/strain distributions at the top and at the bottom fibers of the specimen in the connection region approximately represent those in a uniform axial test of the same magnitude. This requirement is possible when the wall thickness of the specimen is small in comparison to its diameter so that the stress gradient across the wall under bending loads can be adequately approximated by a uniform membrane load.

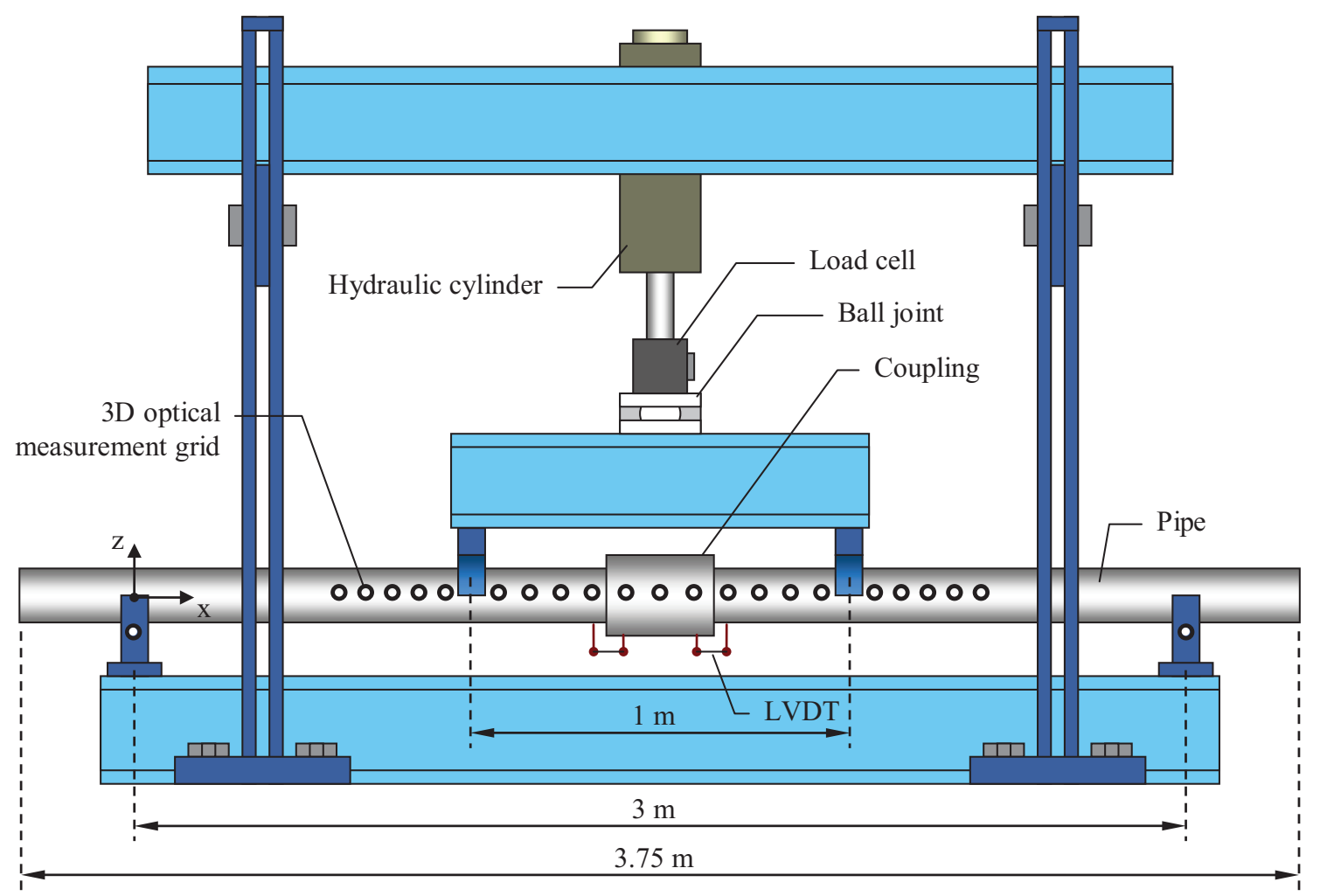

Figure 1: The schematic view of the fatigue test in a four point bending setup.

The assembled specimen consists of two standard API Threaded Linepipes 4.5" with an outside diameter of $114.3 \mathrm{~mm}$ and a thickness of $6.0 \mathrm{~mm}$ (thickness to diameter ratio is about 1/19) to be connected by a threaded coupling (box). The coupling has an outside diameter of $132.1 \mathrm{~mm}$ and a length of $114.3 \mathrm{~mm}$. The specimen (3.750 $\mathrm{m}$ in length) is positioned on two supports $-3 \mathrm{~m}$ apart - on a rigid stiffened foundation beam (Figure 1).

The tested beam was subjected to a cyclic load at $2 \mathrm{~Hz}$ with $7000 \mathrm{~N}$ amplitude in a four-point bending test setup until a fatigue crack propagated. A force range from $-2000 \mathrm{~N}$ to $-16000 \mathrm{~N}$ was applied by a hydraulic cylinder that is connected to a transverse stiff steel beam by a ball hinge. This beam transmits the load to two points at a distance of $1 \mathrm{~m}$ on the tested specimen (that are equally spaced apart from each end, sufficient to exclude the influence of the perturbed stress field around the point loads on the stress distribution of the coupling). This configuration enables the system to create a given uniformly distributed bending moment at the coupling region, resulting from a vertical loading force. It took about 30000 load cycles before fatigue occurred.

A series of modal testing are performed before, during and after the fatigue test. Before and after the fatigue test, vibration measurement is performed in a 2-support configuration (simply supported). During the fatigue test dynamic measurement is carried out after every 1000 cycles in a 4-support configuration with the load is at maximum. At some intervals, the modal test is also performed while the fatigue test is ongoing. The measured input for the modal test is the impulse loading from a load cell that is fixed at the hammer head. The measured output is a spectrum of acceleration together with the dynamic strain signals. These signals then produce the modal strains that use to calculate the modal curvature rather than indirectly being estimated from the mode shape information by finite different approximation. 




Figure 2: The schematic view of the dynamic measurement grid.

The instrumentation for the modal test is included in Figure 2. Accelerometers (a01 to a19) are attached along and at the top of the specimen, except for a06 and a13, which are at the bottom. Sensors a09 and a10 are on the coupling. Accelerometer a19 is positioned at the end of the specimen, where there is a restraint device with a mass of $2.23 \mathrm{~kg}$. Two extra accelerometers are placed on the loading frame and on the supporting beam. Ten dynamic strain gages (s301 to s310) are grouped in five sections near the two supports at the top and at the bottom fibers of the pipe.

In each modal test the two impact hammer positions are at node 16 (position a) and at node 08 (position b). In this way, both input (force) and output (acceleration) of one identical node can be measured. Therefore the identified mode shapes can be mass normalized and it is possible to combine two tests ( $a$ and $b$ ) into a single set of modal parameters. The schematic view of the (dynamic) measurement setup is shown in Figure 2, the coordinates of the grid are given in Table 1.

Reference-based combined deterministic-stochastic subspace identification (CSI/ref) method is used with two reference accelerometer channels (node 8 and node 16) plus one reference channel from one of the dynamic strain gages. Half number of block rows is 50 and model order vector is 2:2:140.

Table 1: The coordinates of the (dynamic) measurement grid.

\begin{tabular}{lcccc}
\hline & $\mathrm{X}(\mathrm{m})$ & $\mathrm{Y}(\mathrm{m})$ & $\mathrm{Z}(\mathrm{m})$ & Note \\
\hline $\mathrm{a} 01$ & -0.376 & & & \\
$\mathrm{a} 02$ & 0.000 & 0 & 0 & Support 1 \\
$\mathrm{a} 03$ & 0.182 & 0 & 0 & \\
$\mathrm{a} 04$ & 0.600 & 0 & 0 & \\
$\mathrm{a} 05$ & 0.800 & 0 & 0 & \\
$\mathrm{a} 06$ & 1.000 & 0 & 0 & Load point 1 \\
$\mathrm{a} 07$ & 1.200 & 0 & 0 & \\
$\mathrm{a} 08$ & 1.400 & 0 & 0 & \\
$\mathrm{a} 09$ & 1.465 & 0 & 0 & \\
$\mathrm{a} 10$ & 1.535 & 0 & 0 & \\
$\mathrm{a} 11$ & 1.600 & 0 & 0 & \\
$\mathrm{a} 12$ & 1.800 & 0 & 0 & \\
$\mathrm{a} 13$ & 2.000 & 0 & 0 & \\
$\mathrm{a} 14$ & 2.200 & 0 & 0 & \\
$\mathrm{a} 15$ & 2.400 & 0 & 0 & \\
$\mathrm{a} 16$ & 2.595 & 0 & 0 & \\
$\mathrm{a} 17$ & 2.816 & 0 & 0 & \\
$\mathrm{a} 18$ & 3.000 & 0 & 0 & \\
$\mathrm{a} 19$ & 3.347 & 0 & 0 & \\
& 3.374 & & &
\end{tabular}




\begin{tabular}{lcccc}
\hline & $X(m)$ & $Y(m)$ & $Z(m)$ & Note \\
\hline s301 & 0.130 & 0 & $57.15 E-3$ & At the top \\
s302 & 0.130 & 0 & $-57.15 E-3$ & At the bottom \\
s303 & 0.194 & 0 & $57.15 E-3$ & \\
s304 & 0.194 & 0 & $-57.15 E-3$ & \\
s305 & 0.233 & 0 & $57.15 E-3$ & \\
s306 & 0.233 & 0 & $-57.15 E-3$ & \\
s307 & 2.763 & 0 & $57.15 E-3$ & \\
s308 & 2.763 & 0 & $-57.15 E-3$ & \\
s309 & 2.791 & 0 & $57.15 E-3$ & \\
s310 & 2.791 & 0 & $-57.15 E-3$ & \\
\hline
\end{tabular}

Besides modal tests, the vertical displacements of the specimen are continuously monitored using a 3D optical measurement system. A measurement was performed after every 1000 cycles of the fatigue test. The optical measurement grid with reflective marker stickers is schematically shown in Figure 1 . Since fatigue cracks are expected to initiate from the last engaged thread of either pin, two LVDTs are mounted at either side of the box (Figure 1), to measure the axial distance between the edge of the box and a point on the pipe body of the pin. When a crack starts to grow, the crack tip opening can be observed by subtracting the elastic deformation from the measured values. The treatment of the displacement and crack opening measurement, however, falls outside the scope of this paper and will not be mentioned thereupon.

\subsection{Modal analysis results}

\subsubsection{2-support configuration:}
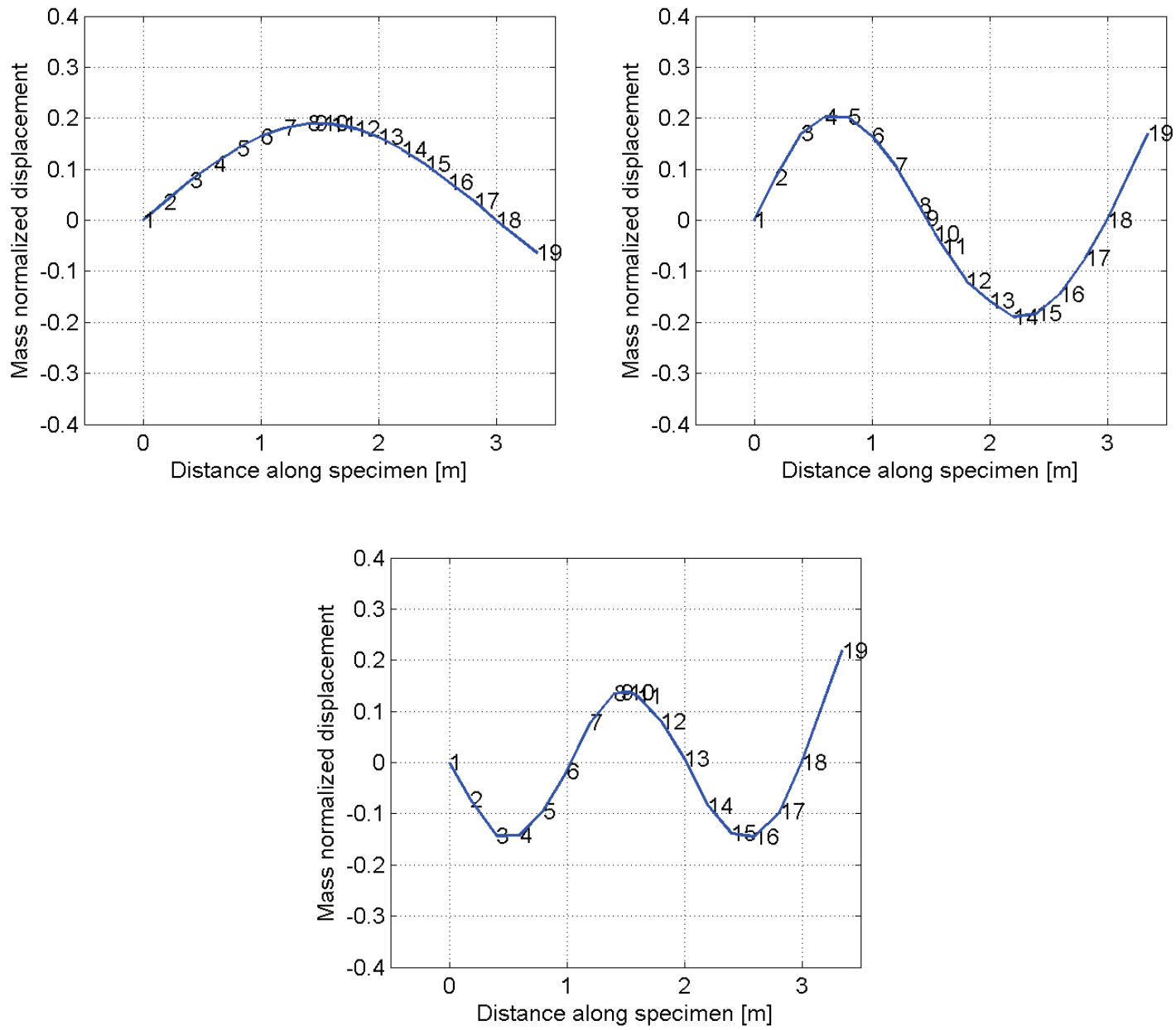

Figure 3: Mode shapes of the first three bending modes in the 2-support configuration (intact specimen). 
In this configuration, one test is carried out before the fatigue test and another is done after the fatigue test. The Reference-based Combined Deterministic-Stochastic Subspace Identification (CSI/ref) is used. This algorithm has been coded into a MATLAB toolbox - MACEC 3.1 - at the Civil Engineering Department of K.U.Leuven $[1,16]$. The first three in-plane bending modes (Figure 3 ) have been initially identified with frequencies of $35.86 \mathrm{~Hz}, 125.19 \mathrm{~Hz}$ and $253.79 \mathrm{~Hz}$. The identified modal properties are given in Table 2 . The quality of mode 1 and mode 2 is generally better than that of mode 3 . The modal phase colinearity (mpc) value $[0 ; 1]$ indicates the realness of an identified mode. It should be close to 1 for a real mode. The mean phase $(\mathrm{mp})$ value [0;90] should be close to 0 degree for a real mode. The mean phase deviation $(\mathrm{mpc})$ value is the deviation of the mean phase.

Table 2: The identified modal properties of the first three bending modes in the 2-support configuration.

\begin{tabular}{lll}
\hline Mode 1 bending & Mode 2 bending & Mode 3 bending \\
\hline $\mathrm{f}=35.86 \mathrm{~Hz}$ & $\mathrm{f}=125.19 \mathrm{~Hz}$ & $\mathrm{f}=253.79 \mathrm{~Hz}$ \\
damping $=2.59 \%$ & damping $=2.14 \%$ & damping $=4.62 \%$ \\
$\mathrm{mpc}=0.9997$ & $\mathrm{mpc}=0.9932$ & $\mathrm{mpc}=0.8613$ \\
$\mathrm{mp}=6.72$ degree & $\mathrm{mp}=2.44$ degree & $\mathrm{mp}=23.38$ degree \\
$\mathrm{mpd}=1.68$ degree & $\mathrm{mpd}=3.34$ degree & $\mathrm{mpd}=11.09$ degree \\
\hline
\end{tabular}

(f: frequency; mpc: modal phase colinearity; mp: mean phase; mpd: mean phase deviation.)

\subsubsection{4-support configuration:}

Modal tests on this configuration are performed after every 1000 cycles of the fatigue test. Two load points consequently act as two immediate supports. The Reference-based Combined Deterministic-Stochastic Subspace Identification (CSI/ref) is employed. From time to time, modal tests are also carried out while the fatigue test was on-going (modal tests on top of the fatigue test). This measurement is done at roughly every 5000 -cycle frequence.

The first two bending modes have been clearly identified at frequencies of $227.61 \mathrm{~Hz}$ and $261.41 \mathrm{~Hz}$ (see Figure 4). The quality of the first mode is not as good as the second one, especially when its frequency eventually reduced to $212.02 \mathrm{~Hz}$ at the end of the fatigue test (30000 cycles), probably due to its eigenfrequency is close to the hydraulic pump frequency of around $220 \mathrm{~Hz}$.

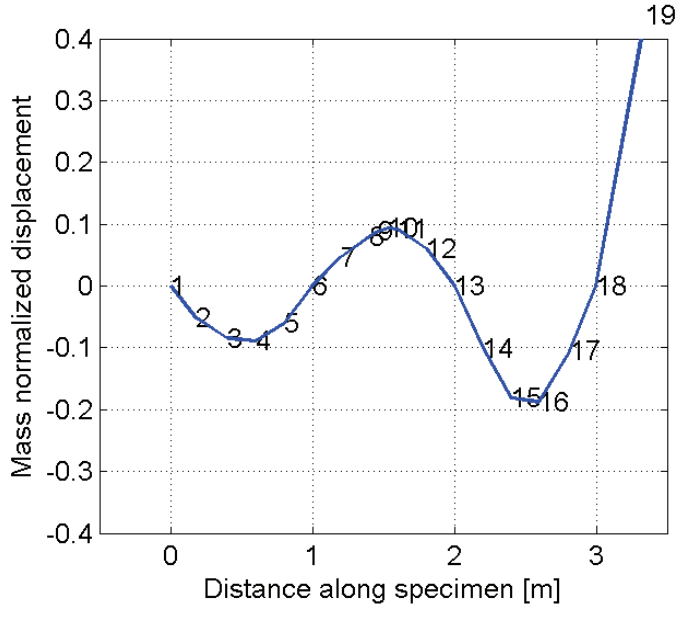

Mode 1 (intact), $f=227.61 \mathrm{~Hz}$

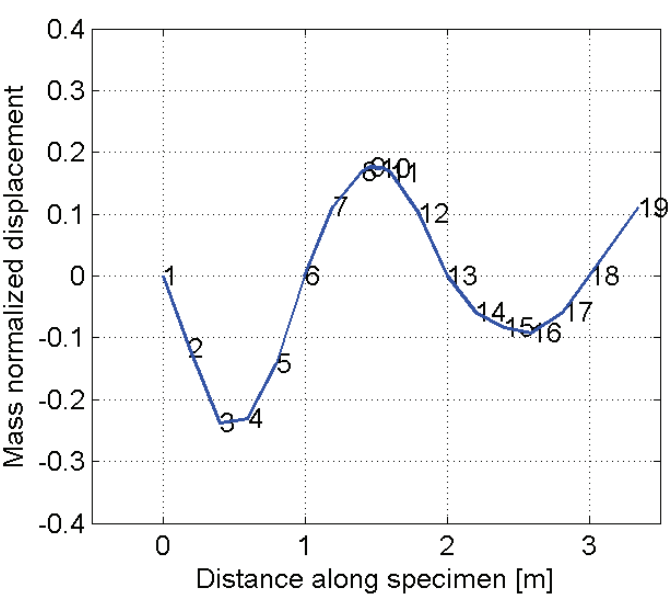

Mode 2 (intact), $f=261.41 \mathrm{~Hz}$

Figure 4: Intact specimen - mode shapes of the first two bending modes in 4-support configuration.

For bending mode 1, the first reduction in frequency (Figure 5) is observed after 11000 cycles. The timing of the frequency reduction in the second bending mode (Figure 4) is more difficult to identify than that of the first mode. It might happen even before 5000 cycles. The reason might be due to the accumulated plastic local deformation in the last engaged thread (LET) zones of the connection without significant loss of global stiffness. The changes in bending mode shapes are insignificant and inconclusive to differentiate whether the damage is to the left or to the right of the coupling at this moment (after 11000 cycles). After that, the reduction in frequencies is marginally gradually reduced until 24000 cycles. At this point the crack seems to be large enough to go through to the wall of the pipe [11]. It can now clearly be observed that the damage 
has been to the left of the coupling. Since then the frequency reduces quickly until the end of the test (30000 cycles). The modal properties and the mode shapes of the first two bending modes in the 4-support configuration of the intact specimen and after 11000 cycles are given in Table 3 . The modal tests while the fatigue test is on-going provide consistent results with other modal tests.

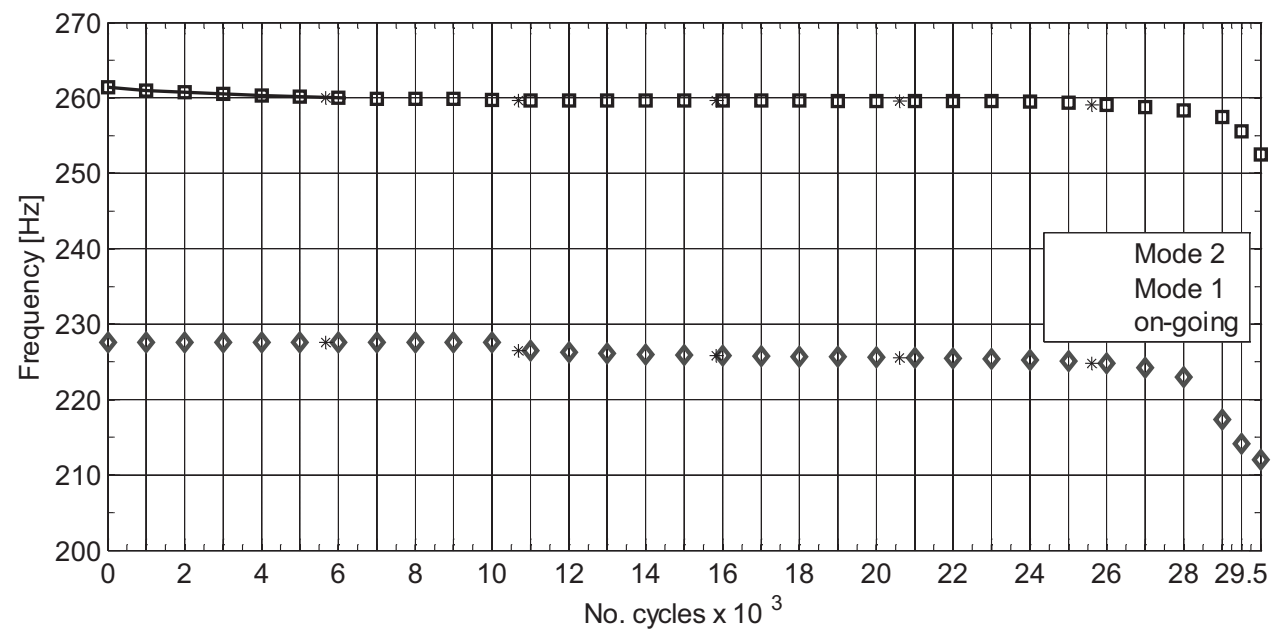

Figure 5: The reduction in frequencies of the first two bending modes in the 4-support configuration.

Table 3: The identified modal properties of the first two bending modes in the 4-support configuration.

\begin{tabular}{|c|c|c|c|}
\hline $\begin{array}{l}\text { Mode } 1 \text { bending } \\
\text { (intact specimen) }\end{array}$ & $\begin{array}{l}\text { Mode } 2 \text { bending } \\
\text { (intact specimen) }\end{array}$ & $\begin{array}{l}\text { Mode } 1 \text { bending } \\
\text { (after } 11000 \text { cycles) }\end{array}$ & $\begin{array}{l}\text { Mode } 2 \text { bending } \\
\text { (after } 11000 \text { cycles) }\end{array}$ \\
\hline model order: 38 & model order: 44 & model order: 25 & model order: 47 \\
\hline$f=227.61 \mathrm{~Hz}$ & $f=261.41 \mathrm{~Hz}$ & $f=226.49 \mathrm{~Hz}$ & $f=259.69 \mathrm{~Hz}$ \\
\hline damping $=2.34 \%$ & damping $=1.42 \%$ & damping $=3.00 \%$ & damping $=1.39 \%$ \\
\hline $\mathrm{mpc}=0.9919$ & $\mathrm{mpc}=0.9949$ & $\mathrm{mpc}=0.9930$ & $\mathrm{mpc}=0.9930$ \\
\hline $\mathrm{mp}=5.31$ degree & $\mathrm{mp}=1.7191$ degree & $\mathrm{mp}=16.90$ degree & $\mathrm{mp}=2.59$ degree \\
\hline $\mathrm{mpd}=4.02$ degree & $\mathrm{mpd}=1.69$ degree & $\mathrm{mpd}=3.04$ degree & $\mathrm{mpd}=1.12$ degree \\
\hline
\end{tabular}

\subsubsection{Modal curvatures:}



Figure 6: The modal curvatures of the original specimen in the 2-support configuration.

As mentioned earlier, dynamic strain sensors (PCB ICP 740B02) are attached to the specimen at five different sections at the top and at the bottom of the speciemen. From the extracted measured modal strains, the modal curvatures can be directly calculated using the following fomula:

$$
\kappa=\frac{\varepsilon_{1}-\varepsilon_{2}}{z_{12}}
$$


With $\varepsilon_{1}$ is modal strain at the top and $\varepsilon_{2}$ is modal strain at the bottom of the section and $z_{12}$ is the vertical distance between these two strain sensors $(114.3 \mathrm{~mm})$. If only accelerations had been measured, the modal curvatures would have to be calculated from the measured modal displacements, using a numerical differentiation procedure, e.g., a central difference approximation [17].

The modal curvature values of the first three bending mode shapes of the specimen in the 2-support configuration of the original specimen are given in Figure 6. Numerical modal curvature shapes of the intact specimen, which is obtained from beam theory, also be given for reference. It is noted that only the results for section 2, 3 and 4 are included as to avoid the influence of local stress concentration leading to the ovalization of the cross sections near the supports (section 1 and 5). It can be seen that the measured modal curvatures match the beam model theory ones well. The measured modal curvature values stay almost unchanged throughout the fatigue test as the measured sections are far from the localized damaged zones in the coupling except for bending mode 3 , which witnesses minor changes.

\section{FINITE ELEMENT MODEL UPDATING}

In FE model updating, the numerical modal data are initially computed using estimated starting values for the unknown model parameters to be updated. These parameters are then adjusted until the discrepancies between the numerical and experimental modal data are minimized. The formulation of the objective function involves some error norms, appropriate bounds and constraints. Data fitting is usually done by means of an error minimization technique, where the distance between prediction vectors of the computational model (eigenfrequencies, mode shapes, modal strains, etc.) and measurements of the corresponding experiment is minimized. In most cases, the least square norm of the residuals is preferred in engineering computations due to its differentiability and ease of implementation.

Two different updating processes are performed, in order to appropriately model the original and the damaged state of the connected specimen. Special boundary condition has to be made to the test setup because of the nature of the specimen is rounded thin walled structure. The specimen is rounded, therefore the roller bearing that is typically applied to the conventional rectangular beam is not suitable. Since the pipe is considered as thin walled structure, the support has to be relatively flexible in order to avoid the local ovalization of the pipe, which might has some effects on the quality of the identified mode shapes.

In the first updating process the vertical stiffness values of the two supports are updated. In the second process, the bending stiffness moduli of the different zones in the coupling region are updated. Since the damage is expected to be in this region. Details of the formulation to a least square problem can be referred to Bui et al. [18].

The finite element model includes 51 BEAM188 elements (in the Ansys Element Library [19]). The support is modelled by two ComBIN14 spring elements with an initial stiffness of $5 \times 10^{7} \mathrm{~N} / \mathrm{m}$. Only the outer boundary surface of the coupling region is considered. Therefore the contact nature among connecting threads is not taken into account. The five different zones in the coupling region are as follow: the thread run-out on the left tube, the thread engaging to the left, the middle coupling, the thread engaging to the right, the thread run-out on the right tube.

In the first updating stage, two identification parameters are sought for, i.e. the spring stiffness of the two supports. The input of the cost function is the differences in the mass normalized mode shapes of the first three bending modes and their associated frequencies. The modal curvature values are not included because the gauges are purposively mounted far from the damage zones in the middle of the specimen. And it is believed that the change in modal curvature is only significant locally near the damaged region [17]. A hybrid algorithm (Genetic Algorithm followed by a Trust Region Newton local search) is again used [18]. The resulting spring stiffness is found to be $479 \times 10^{7} \mathrm{~N} / \mathrm{m}$ and $256 \times 10^{7} \mathrm{~N} / \mathrm{m}$. These values are used in the FE model in the damage identifying stage.

In the second updating stage, five identification parameters are sought for: these are the bending stiffness of difference zones in the coupling region. In both updating stages, normalized identification factors are used in order to avoid the convergence problem in optimization procedure. The initial values of the factors are very small numbers (reflecting undamaged situation). If, the updating values were found close to unity, the corresponding stiffness would be totally loss. The obtained updated factor is $a_{E}=\{0.8485 ; 0.1192$; $0.0934 ; 0.1270 ; 0,4517\}^{\top}$. The stiffness is virtually no loss at the middle zone of the coupling. Small stiffness degradation in the thread connecting zone means that the connection is quite secured (tight) in the fatigue life. The loss is concentrated in the last engaged thread zones of the connection. The bigger value is witnessed at the left side of the coupling, which is conformed to visual inspections of the specimen afterward. 


\section{CONCLUSIONS}

In this paper, an experimental modal approach is used to detect and to assess the fatigue damage in the threaded connection of a medium size tabular structure. The fatigue test is based on a four-point bending test setup. Reference-based Combined Deterministic-Stochastic Subspace Identification method is capable of extracting modal parameters of the structure while the fatigue load is still acting on the specimen, which means a four-point bending becomes a 4-support configuration and condition of the connected structure can be monitored continuously during the fatigue test. An updating procedure, which consists of two steps, is proposed to find the stiffness of the supports and to assess the damage in different zone of the coupling due to fatigue. From the resulting degrading stiffness distribution in the box region, large reduction is found in the thread run-out zones, which suggests a proper detailing is this zone might improve the fatigue performance of this particular connection.

The use of low cost sensors for dynamic strain measurement is a step forward in OMAX testing. The extracted modal strains in different mode shapes can be used to directly calculate the modal curvature to complement the reduction in frequencies and the changes in mode shapes to detect timely the initiation of the fatigue crack which is by nature difficult to identify and assess even in laboratory conditions.

Future work is to apply the dynamic strain sensors close the expected damage location and to use the FE updating framework the whole loading history of the test in order to quantify the stiffness degradation of the threaded connection region continuously. Then the same methodology can be applied to a large scale testing in a resonant bending machine for pipes [20] that is currently being developed at the Soete Laboratory, Ghent University.

\section{ACKNOWLEDGEMENTS}

The authors would like to acknowledge the financial support from the BOF fund B/04939 of the Ghent University and from the Research Foundation - Flanders (FWO), Belgium, project G.0228.06N.

\section{REFERENCES}

[1] Reynders, E., De Roeck, G., Reference-based combined deterministic-stochastic subspace identification for experimental and operational modal analysis, Mechanical Systems and Signal Processing, 22(3): 617 - 637, 2008.

[2] Reynders, E., Pintelon, R., De Roeck, G., Uncertainty bounds on modal parameters obtained from Stochastic Subspace Identification; Mechanical Systems and Signal Processing, 22(4): 948 - 969, 2008.

[3] Peeters, B., De Roeck, G., Stochastic system identification for operational modal analysis: A review, ASME Journal of Dynamic Systems, Measurement, and Control, 123(4): 659 - 667, 2001.

[4] Friswell, M.I., Mottershead, J.E., Finite element model updating in structural dynamics, Kluwer Academic Publishers Group, 1995.

[5] Teughels, A., Maeck, J., De Roeck, G., Damage assessment by FE model updating using damage functions, Computers and Structures, 80(25): 1869 - 1879, 2002.

[6] Reynders, E., Teughels, A. and De Roeck, G., Finite element model updating and structural damage identification using OMAX data, Mechanical Systems and Signal Processing, 24(5):1306 - 1323, 2010.

[7] Ewins, D.J., Modal Testing: Theory and Practice, second edition, Research Studies Press, Baldock, UK, 2000.

[8] Heylen, W., Lammens, S., Sas, P., Modal Analysis Theory and Testing, Department of Mechanical Engineering, Katholieke Universiteit Leuven, Belgium, 1997.

[9] Guillaume, P., De Troyer, T., Devriendt, C., De Sitter, G., OMAX - a combined experimentaloperational modal analysis approach. In: Sas, P., De Munck, M. (Eds.), Proceedings of ISMA2006 International Conference on Noise and Vibration Engineering, Leuven, Belgium, 2006.

[10] Reynders, E., System identification and modal analysis in structural mechanics. PhD thesis, Department of Civil Engineering, K.U.Leuven, 2009.

[11]Van Wittenberghe, J., De Baets, P., and De Waele, W., Nonlinear Contact Analysis of Different API Line Pipe Coupling Modifications, ASME Journal of Pressure Vessel Technology, 132(5), 2010. 
[12] Van Wittenberghe, J., De Pauw, J., De Baets, P., De Waele, W., Wahab, M.A., and De Roeck, G., Experimental determination of the fatigue life of modified threaded pipe couplings. Procedia Engineering, 2(1): 1849 - 1858, 2010.

[13] Portier L, Calloch S, Marquis D, and Geyer P., Ratchetting under tension-torsion loadings: experiments and modeling, International Journal of Plasticity, 16:303-35, 2000.

[14]Bocher, L. , Delobelle, P. , Robinet, P., and Feaugas, X., Mechanical microstructural investigations of an austenitic stainless steel under non-proportional loadings in tension-torsion internal and external pressure, International Journal of Plasticity, 17:1491-530, 2001.

[15]Delobelle, P., Robinet, P., and Bocher, L., Experimental study and phenomenological modelization of ratchet under uniaxial and biaxial loading on an austenitic stainless steel, International Journal of Plasticity, 11(4): 295-330, 1995.

[16] Reynders, E., Schevenels, M., and De Roeck, G., MACEC 3.1: a MATLAB toolbox for experimental and operational modal analysis: user's manual, Techincal Report BWM-2010-05, Katholieke Universiteit Leuven, Departement of Civil Engineering, 2010.

[17] Abdel Wahab, M., and De Roeck, G., Damage detection in bridges using modal curvatures: Application to a real damage scenario, Journal of Sound and Vibration, 226(2), 217-235, 1999.

[18] Bui, T.T., De Roeck, G., Van Wittenberghe, J., De Baets, P., and De Waele, W. A modal approach to identify fatigue damage in threaded connections of large scale tubular structures. In Sas, P., and Bergen, B. Edition, Proceedings of the International Conference on Noise and Vibration Engineering, ISMA2010, 795-807, 2010.

[19]Ansys, Inc., Elements Reference - Ansys Release 11.0, 2007.

[20]Van Wittenberghe, J., De Pauw, J., De Baets, P., De Waele, W., Ost, W., De Roeck, G., and Bui, T.T., Fatigue investigation of threaded pipe connections. In Van Wittenberghe, J. (Ed.), Sustainable Construction \& Design, Volume 1. Day of research, Laboratory Soete - Ghent University, 2010. 